Original article

\title{
CLINICAL, HAEMATOLOGICAL AND BLOOD BIOCHEMICAL PARAMETERS IN ARABIAN ONE-HUMPED CAMELS (CAMELUS DROMEDARIUS) WITH BABESIA CABALLI INFECTION
}

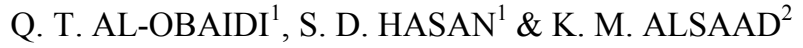 \\ ${ }^{1}$ Department of Internal and Preventive Medicine, College of Veterinary \\ Medicine, University of Mosul, Iraq; ${ }^{2}$ Department of Internal and Preventive \\ Medicine, College of Veterinary Medicine, University of Basrah, Iraq
}

\section{Summary}

Al-Obaidi, Q. T., S. D. Hasan \& K. M. Alsaad, 2021. Clinical, haematological and blood biochemical parameters in Arabian one-humped camels (Camelus dromedarius) with Babesia caballi infection. Bulg. J. Vet. Med., 24, No 3, 422-433.

This study was conducted to diagnose Babesia caballi in one-humped camels in Nineveh governorate, Iraq, using microscopic examination and conventional polymerase chain reaction (PCR) and to evaluate the clinical, haematological and blood biochemical parameters in camels. A total of 62 camels from local breeds, 2-7 years old from both sexes, reared in Nineveh Governorate, were naturally infected with $B$. caballi and 12 clinically healthy camels were used as controls based on clinical and laboratory examination. Babesia caballi was diagnosed as pear-shaped organisms, existing mainly in pairs within the erythrocytes in blood smears stained by Giemsa, with mean parasitaemia rate $8.59 \pm 0.13 \%$. Blood smears stained by acridine orange and conventional PCR confirmed $\mathrm{B}$. $\mathrm{Ca}$ balli diagnosis. Infected camels were found to be suffering from partial or total loss of appetite, emaciation, pale mucous membranes, irregular heart beats, rough hair coat, digestive disturbances, haemoglobinuria and presence of ticks on various body parts. There was considerably elevated body temperature, respiratory and heart rates among infected camels in comparison with control groups. Haematological examinations indicated a statistically significant $(\mathrm{P}<0.05)$ decrease in red blood cell counts, haemoglobin and haematocrit with macrocytic hypochromic anaemia. Additionally, leukocytosis due to significant $(\mathrm{P}<0.05)$ rise in total leukocyte count and lymphocytes in infected camels in comparison with controls besides a significant $(\mathrm{P}<0.05)$ decrease in platelet count and fibrinogen were demonstrated. On the other hand, the mean platelet volume, platelet distribution width, clotting time, prothrombin time and activated partial thromboplastin time were significantly $(\mathrm{P}<0.05)$ elevated in infected camels vs control. Biochemical analysis revealed significant $(\mathrm{P}<0.05)$ rise in troponin $\mathrm{I}$, creatine phosphokinase myocardial band and lactate dehydrogenase in infected camels compared to healthy animals. This study concluded that $B$. caballi infected camels might be endemic in Nineveh governorate, Iraq. Babesia caballi in camels causes clinical, haematological, and blood biochemical changes.

Key words: Babesia caballi, blood biochemistry camels, clinical signs, haematological changes 


\section{INTRODUCTION}

The one-humped camel (Camelus dromedaries) is anatomically and physiologically adaptable for life in very difficult environments in the dry and semi-dry regions of the world and are commonly found in certain parts of Africa, Arabian countries as well as the West of Asia up to India (Wernery \& Kaaden, 2002; AL-Ani, 2004). Camels are an important source of milk, wool and meat; however, they are also used for transport and might also be considered as draught animals (Kamani et al., 2008).

In one-humped camels (Camelus dromedarius), babesiosis results mainly from infection with Babesia caballi and Babesia equi (Swelum et al., 2014). Susceptibility to the disease appears to be unaffected by age, sex and animal species (Abdelrahim et al., 2009). The transmission of $B$. caballi is mostly through the ixodid tick species including: Amblyomma spp., Hyalomma spp., Rhipicephalus spp., Dermacentor spp., Ixodes spp., and Haemaphysalis spp. (Hassan \& Salih, 2009; Scoles \& Ueti, 2015), and also Anocentor nitens ticks (Abd-Elmaleck et al., 2014). Babesia caballi can infect ponies, horses, donkeys, mules (Kouam et al., 2010; AlObaidi et al., 2016) cattle, sheep and goats (Zhang et al., 2015), dogs (Gabrielli et al., 2015), camels (Qablan et al., 2012) and humans (Ash \& Orinel, 1990; Uilenberg, 2006). Camel's babesiosis is also referred to as camel's piroplasmosis. It is endemic in most tropical and subtropical parts of the world (Egbe-Nwiyi, 1994). The piroplasms especially Babesia caballi have been reported in camels in Iraq (Jasim et al., 2015), Egypt (Abd-Elmaleck et al., 2014), Jordan (Qablan et al., 2012), Iran (Khamesipour et al., 2015), and Sudan (Ibrahim et al., 2017).
Generally, camel babesiosis is manifested by continuous fever, inappetence, progressive anaemia, haemoglobinuria, pale and/or icteric mucous membranes, gastrointestinal stasis, emaciation and death which might also occur in the final stages (Qablan et al., 2012). Moreover, Swelum et al. (2014) found that camels naturally infected with babesiosis have clinical, haematological and biochemical parameters changes. Programmes for control of blood parasite are not commonly available (Hairgrove et al., 2015).

A suspected case of camel piroplasmosis can be identified based on the clinical manifestation of the infected camels (FAO, 2014; Swelum et al., 2014). To confirm a suspected case, different laboratory diagnostic techniques have been developed for camel piroplasmosis including microscopic examination of blood smears, serological tests and molecular approaches (Ganjali, 2016; Faraj et al., 2018).

The information on camel babesiosis in Nineveh governorate is scant. Therefore, the main goals of the present work were to diagnose Babesia caballi in camels using microscopic examination and conventional polymerase chain reaction and to evaluate clinical, haematological and blood biochemical parameters.

\section{MATERIALS AND METHODS}

\section{Animals and study area}

The study was conducted on 62 local breed camels, 2-7 years old and from both sexes reared in the Gogjalee region in Nineveh governorate, Iraq, naturally infected with $B$. caballi and 12 clinically healthy local camels considered as controls based on clinical and laboratory examination. Complete clinical and labora- 
Clinical, haematological and blood biochemical parameters in Arabian one-humped camels ....

tory examinations were applied for all animals using the routine clinical and laboratory methods.

\section{Samples collection}

From September 2018 to March 2019, blood samples were withdrawn from each camel via the jugular vein using $18 \mathrm{G}$ needle into three sterile Vacutainer ${ }^{\circledR}$ tubes (5 $\mathrm{mL}$ each), one with ethylenediaminetetraacetic acid (EDTA) anticoagulant for complete blood counts and PCR, a second tube with trisodium citrate from which plasma was separated for blood clotting indices estimation and a plain tube for obtaining serum for biochemical analysis.

\section{Blood smears examination}

A total of 124 blood smears, consisting of thin and thick blood smears $(n=62)$ were prepared, air-dried, fixed in absolute methanol, stained with $10 \%$ Giemsa stain and observed under light microscope to identify the parasites and estimate the parasitaemia rate. The latter was calculated following the equation of Fritsche \& Smith (2001): Parasitaemia (\%) = (number of infected RBCs/number of counted RBS) $\times 100$.

Furthermore, the fluorochrome $0.01 \%$ acridine orange was also used to stain blood smears $(n=62)$ for examination under fluorescent microscope as a confirmatory diagnosis of parasites (Ciancaglini et al., 2005).

\section{Conventional PCR technique}

Genomic DNA was obtained from the camel's blood samples employing the QIAamp ${ }^{\circledR}$ DNA Mini Kit (QIAgen GmbH, Hilden, Germany). The concentration and purity of the DNA yield from of camel's blood samples were established by utilising Nanophotometer ${ }^{\mathrm{TM}}$ P-Class (IMPLEN, Germany). The concentration of the sample was measured by absorbance (A) at wavelength $260 \mathrm{~nm}$. It was found to range from 42-90 ng while, the purity was an $\mathrm{A}_{260} / \mathrm{A}_{280} \mathrm{~nm}$ ratio of 1.7-1.9.

The hypervariable V4 region of $18 \mathrm{~S}$ $r R N A$ gene of $B$. caballi from camel blood $(\mathrm{n}=62)$ was amplified as a target in conventional PCR technique. The oligonucleotide primers were designed by Sloboda et al. (2011) and obtained from First BASE Laboratories Sdn. Bhd. Malaysia (Table 1). PCR reactions were carried out in a total volume of $25 \mu \mathrm{L}$, consisting of $12.5 \mu \mathrm{L}$ commercial Master Mix (1st BASE Pte Ltd, Singapore), $20 \mu \mathrm{M}$ of each primer and $20 \mathrm{ng}$ of genomic DNA. The mixture was pre-denatured for $5 \mathrm{~min}$ at 95 ${ }^{\circ} \mathrm{C}$, then subjected to denaturation for $45 \mathrm{~s}$ at $94{ }^{\circ} \mathrm{C}$, annealed for $45 \mathrm{~s}$ at $60.5{ }^{\circ} \mathrm{C}$, with extension for $30 \mathrm{~s}$ at $72{ }^{\circ} \mathrm{C}$, finally extended for $10 \mathrm{~min}$ at $72{ }^{\circ} \mathrm{C}$; and $36 \mathrm{cy}$ cles were repeated. The amplified DNA samples were subjected to electrophoresis on $1.5 \%$ agarose gel stained with MidoriGreen to visualise the amplified DNA fragment in the Gel Doc ${ }^{\mathrm{TM}} \mathrm{EZ}$ imager (BIO RAD/ USA).

Table 1. Oligonucleotide primers used for amplification of the parasite $18 S r R N A$ genes

\begin{tabular}{llcc}
\hline Primers & Sequences 5'-3' & nmoles & Expected size (bp) \\
\hline TBM_F & CTT CAG CAC CTT GAG AGA AAT & 22.6 & 650 \\
BC_R & GAT TCG TCG GTT TTG CCT TGG & 21.3 & \\
\hline
\end{tabular}




\section{Haematological and biochemical analysis}

Blood was used for haematology analysis, including total red blood cell count (TRBc), packed cell volume (PCV), haemoglobin concentration $(\mathrm{Hb})$, total leukocyte counts (TLC), platelet count (Plt), mean platelet volume (MPV), platelet distribution width (PDW), mean corpuscular volume (MCV) and mean corpuscular haemoglobin concentration (MCHC) using haematology analyser (Genex, USA). Thin, dry, fixed Giemsa-stained blood smears were utilised for differential leukocyte counts (Weiss \& Wardrop, 2010).

Plasma was used to determine the prothrombin time (PRT), activated partial thromboplastin time (APTT) and fibrinogen, employing commercial kits (Biolabo, France). Clotting time (CT) was estimated according to Bush (1975). Furthermore, troponin-I (cTn-I) was evaluated in camel sera with a commercially available cTn-I enzyme-linked immunosorbent assay (ELISA) kit (EAGLE, Biosciences, Italy). Additionally, creatine phosphokinase myocardial band (CpK-MB) and lactate dehydrogenase (LDH) were spectrophotometrically measured using commercial kits (Roche Diagnostics, Indianapolis, GMBH, Germany).

\section{Statistical analysis}

The differences between camels infected with Babesia caballi and healthy camels (controls group) were evaluated statistically employing Student $t$-test (SPSS) (Leech, 2007).

\section{RESULTS}

In the current study, Babesia caballi was diagnosed in 62 local camels. The pearshaped B. caballi existed, mainly in pairs, within the erythrocytes in blood smears

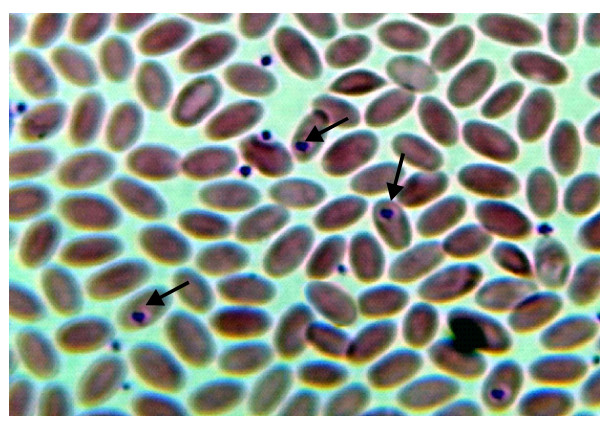

Fig. 1. Blood smears stained by Giemsa $10 \%$, showing Babesia caballi inside the camel erythrocytes, under oil immersion $100 \times$.

stained with Giemsa 10 and fluorochrome acridine orange (Fig. 1, 2). The parasitaemia rate ranged from 4 to $9 \%$ (mean $8.59 \pm 0.13 \%$ ). Moreover, as a confirmation for the diagnosis of $B$. caballi infection, the conventional PCR technique exhibited the positive bands of the parasite's 18S rRNA gene (Fig. 3).

This study indicated that the camels naturally infected with $B$. caballi exhibited varying clinical manifestations, including partial or total loss of appetite $(88.7 \%)$, emaciation $(83.8 \%)$, pale mucous membranes $(80.6 \%)$, irregular heart beats by auscultation $(59.6 \%)$, rough hair coat (61.2\%), digestive disturbances (48.3\%), haemoglobinuria $(22.5 \%)$ and existence of ticks on various parts of the body (54.8\%) (Table 2 ). In addition, data concerning clinical examinations of infected camels indicated a considerable rise $(\mathrm{P}<0.05)$ in body temperature, respiratory and heart rates of infected camels compared to the controls (Table 3).

The outcomes of haematological examinations indicated a statistical significant reduction in the mean values of red blood cells, haemoglobin and PCV of B. caballiinfected camels compared to healthy animals, reflectingd macrocytic hypochromic anaemia. In addition, the results further 
Clinical, haematological and blood biochemical parameters in Arabian one-humped camels ....
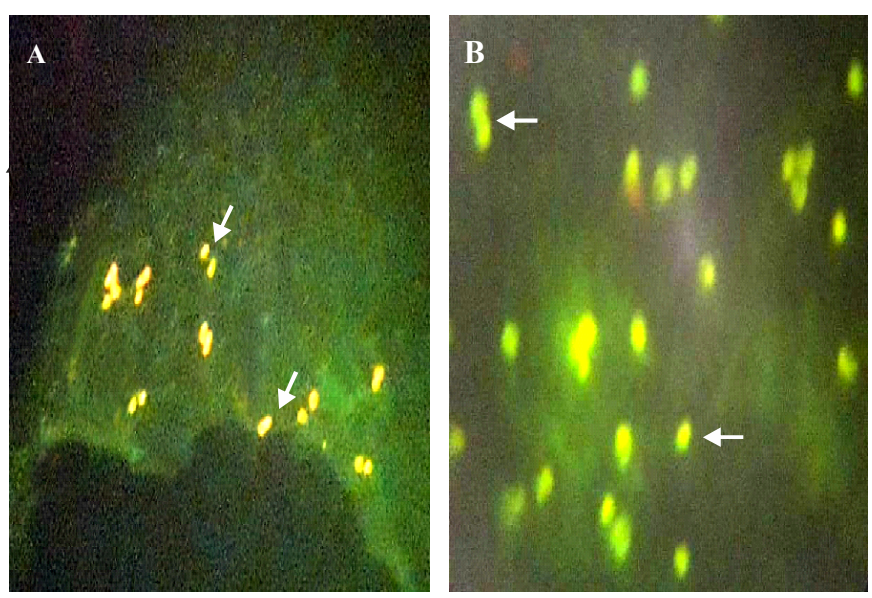

Fig. 2. Blood smears showing Babesia caballi inside the camel erythrocytes using fluorescent microscopy; $0.01 \%$ acridine orange staining. A. $1000 \times$; B. $1800 \times$.

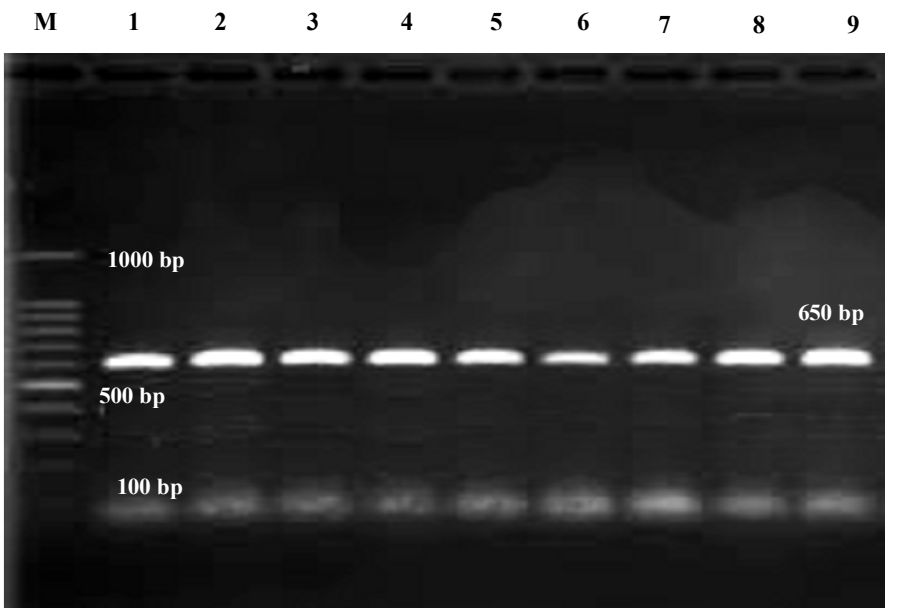

Fig. 3. Gel electrophoresis image exhibiting: lane M. Exact Mark 100-1000 bp DNA ladder; lanes $1-9 ; 18 S$ rRNA in B. caballi infected camels, band size $\sim 650 \mathrm{bp}$.

revealed leukocytosis due to a significant $(\mathrm{P}<0.05)$ increase in the percentage of lymphocytes (lymphocytosis) (Table 4).

On the other hand, results also showed that there were significant differences in clotting factors in camels infected with $B$. caballi compared to healthy animals. Further, results showed a significant $(\mathrm{P}<0.05)$ reduction in total platelets count and fibrinogen in camels with $B$. caballi compared to healthy animals, whereas values of mean platelet volume, platelet distribution width, clotting time, prothrombin time and activated partial thromboplastin time were significantly $(\mathrm{P}<0.05)$ increased in $B$. caballi-infected vs healthy animals (Table 5).

The biochemical analysis indicated a significant $(\mathrm{P}<0.05)$ rise in some cardiac biomarkers -troponin I (cTnI), creatine phosphokinase myocardial band and lac- 
Table 2. Frequency and percentage of clinical manifestations of camels infected with $B$. caballi $(\mathrm{n}=62)$.

\begin{tabular}{lcc}
\hline Clinical manifestations & $\begin{array}{c}\text { Number of camels with } \\
\text { clinical manifestations }\end{array}$ & $\begin{array}{c}\text { Percentage } \\
\%\end{array}$ \\
\hline Partial or total loss of appetite & 55 & 88.7 \\
Emaciation & 52 & 83.8 \\
Pale mucous membranes & 50 & 80.6 \\
Rough hair coat & 38 & 61.2 \\
Irregular heartbeats & 37 & 59.6 \\
Digestive disturbances & 30 & 48.3 \\
Haemoglobinuria & 14 & 22.5 \\
Presence of ticks on different parts of the body & 34 & 54.8 \\
\hline
\end{tabular}

Table 3. Body temperature, respiratory and heart rates of camels infected with $B$. caballi and healthy animals. Data are presented as mean \pm SEM

\begin{tabular}{llc}
\hline Parameters & Healthy camels $(\mathrm{n}=12)$ & Infected camels $(\mathrm{n}=62)$ \\
\hline Body temperature, ${ }^{\circ} \mathrm{C}$ & $38.2 \pm 0.74$ & $39.8 \pm 1.40^{*}$ \\
Respiratory rate, $\mathrm{min}^{-1}$ & $10.4 \pm 2.85$ & $22.8 \pm 6.71^{*}$ \\
Heart rate, $\mathrm{min}^{-1}$ & $32.2 \pm 2.34$ & $62.3 \pm 7.40^{*}$ \\
\hline
\end{tabular}

* $\mathrm{P}<0.05$ between both groups.

Table 4. Blood parameters of camels infected with B. caballi and healthy animals. Data are presented as mean \pm SEM

\begin{tabular}{lcc}
\hline Parameters & Healthy camels $(\mathrm{n}=12)$ & Infected camels $(\mathrm{n}=62)$ \\
\hline $\mathrm{RBC}, \mathrm{T} / \mathrm{L}$ & $7.73 \pm 1.33$ & $4.68 \pm 1.34^{*}$ \\
$\mathrm{Hb}$ g/L & $123 \pm 16.3$ & $82.2 \pm 28.4^{*}$ \\
$\mathrm{PCV}, \%$ & $30.6 \pm 3.78$ & $22.8 \pm 2.92^{*}$ \\
$\mathrm{MCV}, \mathrm{fL}$ & $39.58 \pm 7.83$ & $48.71 \pm 6.28^{*}$ \\
$\mathrm{MCHC}, \mathrm{g} / \mathrm{L}$ & $401.9 \pm 58.3$ & $360.5 \pm 79.2 *$ \\
WBC, G/L & $11.84 \pm 1.83$ & $13.93 \pm 1.22^{*}$ \\
Lymphocytes, \% & $41.3 \pm 2.3$ & $50.2 \pm 2.16^{*}$ \\
Neutrophils, \% & $46.2 \pm 1.76$ & $43.8 \pm 3.87$ \\
Monocytes, \% & $4.5 \pm 0.8$ & $3.9 \pm 0.82$ \\
Eosinophils, \% & $4.17 \pm 0.8$ & $3.22 \pm 0.71$ \\
Basophils, \% & $0.7 \pm 0.14$ & $0.7 \pm 0.11$ \\
\hline
\end{tabular}

* $\mathrm{P}<0.05$ between both groups. 
Clinical, haematological and blood biochemical parameters in Arabian one-humped camels ....

Table 5. Blood clotting indices of camels infected with B. caballi and healthy animals. Data are presented as mean $\pm \mathrm{SEM}$.

\begin{tabular}{lcc}
\hline Parameters & Healthy camels $(\mathrm{n}=12)$ & Infected camels $(\mathrm{n}=62)$ \\
\hline Platelets, G/L & $449 \pm 22.14$ & $322 \pm 11.42^{*}$ \\
MPV, fL & $4.29 \pm 0.72$ & $8.33 \pm 0.61^{*}$ \\
PDW, \% & $12.23 \pm 1.6$ & $18.51 \pm 1.6^{*}$ \\
Clotting time, min & $3.3 \pm 1.2$ & $4.6 \pm 1.85^{*}$ \\
Prothrombin time, $\mathrm{s}$ & $12.5 \pm 5.2$ & $13.8 \pm 4.8^{*}$ \\
Activated partial thromboplastin time, $\mathrm{s}$ & $11.78 \pm 1.6$ & $16.82 \pm 1.78^{*}$ \\
Fibrinogen, g/L & $3.11 \pm 0.77$ & $2.71 \pm 0.84^{*}$ \\
\hline
\end{tabular}

* $\mathrm{P}<0.05$ between both groups.

Table 6. Serum cardiac troponin I and some enzyme activities of camels infected with $B$. caballi and healthy animals. Data are presented as mean \pm SEM.

\begin{tabular}{lcc}
\hline Parameters & Healthy camels $(\mathrm{n}=12)$ & Infected camels $(\mathrm{n}=62)$ \\
\hline Serum cardiac troponin $\mathrm{I}, \mathrm{ng} / \mathrm{mL}$ & $0.33 \pm 0.06$ & $27.21 \pm 1.2^{*}$ \\
CpK-MB, U/L & $54 \pm 12$ & $117 \pm 23^{*}$ \\
$\mathrm{LDH}, \mathrm{U} / \mathrm{L}$ & $455 \pm 78$ & $490 \pm 33^{*}$ \\
\hline
\end{tabular}

$* \mathrm{P}<0.05$ between both groups.

tate dehydrogenase in camels with $B . c a$ balli (Table 6).

\section{DISCUSSION}

There are several studies which have detected the prevalence of camel piroplasmosis (Babesia spp. and Theileria spp.) in different provinces of Iraq including: Southern Iraq with $9.95 \%$ and $5.8 \%$ (Jasim et al., 2015), Najaf province with $31.87 \%$ and $29.37 \%$ (Al-Amery et al., 2017), and Al-Diwaniyah province with 53\% and 46.5\% (Al-Naily, 2018), using different laboratory techniques. In the current study, Babesia caballi has been diagnosed for the first time in local camel breeds in Nineveh governate according to microscopic examinations of thin and thick blood smears stained with Giemsa and fluorochrome acridine orange, ap- pearing as pear-shaped, and existing mainly in pairs within the erythrocytes. These results are consistent with those observed by Swelum et al. (2014), Jasim et al. (2015), Abd-Elmalek et al. (2016) and Ibrahim et al. (2017). The percentage of haemoparasitism of Babesia caballi in infected camels ranged from $4-9 \%$. These findings are similar to those noted by Alsaad et al. (2015) who found that Babesia caballi parasitaemia ranged from 5-8\%. The microscopic detection of piroplasms by visual examination of blood smears stained with Giemsa is the simplest, most rapid and accessible diagnostic method for confirming the clinical cases of piroplasms (Irwin, 2010). In this study, $B$. caballi in camels was diagnosed by conventional PCR technique and the positive bands of the parasite were at approximately $650 \mathrm{bp}$. This outcome concurs with 
the findings of Khamesipour et al. (2015) and Ibrahim et al. (2017) who stated that molecular results clearly confirmed the presence of the parasite.

Camels infected with $B$. caballi exhibited different clinical manifestations which reflected the acute form of the disease. This finding is in congruence with the reports of Qablan et al. (2012), Swelum et al. (2014) and Alsaad et al. (2015). The pale colour of the mucous membranes in camels infected with haemoparasites suggested the presence of anaemia due to decrease in haemoglobin concentration and total erythrocytes count, which occurred because of lysis of erythrocytes and elimination of infected red cells by the reticuloendothelial system (Maharan, 2004). Furthermore, irregular heart beats might be indicative of the first step of cardiac problems. Arrhythmia is defined as an irregular heartbeat, when the heart beats too fast, too slowly, or irregularly, and when the electrical signals to the heart that coordinate heartbeats are not functioning normally (Tharwat et al., 2013). The presence of ticks infesting different parts of the body on infected camels identified them as a significant biological transmitter of the disease (Wernery \& Kaaden, 2002; Apanaskevich et al., 2008). The vital signs of infected camels were observed to change, since increased body temperature might suggest the liberation of pyrogens due to lysis of body cells followed by stimulation of thermoregulatory centres for fever crises. Further, anaemia will decrease blood perfusion, therefore tissue hypoxia will occur, thereby resulting in anaerobic metabolism of decreased perfusion, and respiratory rate will be increased (Maharan, 2004). Higher heart rate in infected camels, which could also be the result of hypoxia (anaemic hypoxia), caused by the de- creased erythrocyte count and haemoglobin concentration which affects oxygen transport to body tissues, leading to tissue deprivation of adequate oxygen supply (Constable et al., 2017)

The outcomes of the present study indicated a macrocytic hypochromic type of anaemia in diseased camels which occurred because of the reduction in haemogram (total erythrocyte count, haemoglobin concentration and packed cell volume). Similar results were also noticed by Abdelrahim et al. (2009) and Ibrahim et al. (2017). The onset of anaemia related to Babesia caballi infection could be due to diverse mechanisms, decreased erythrocyte lifespan due to erythrocyte lysis which is a result of the direct parasitic effect on the infected erythrocytes, and the depression of haematopoietic system which is also a relevant factor (Swelum et al., 2014). In addition, erythrocytes phagocytosis by the macrophages triggered by parasitic damage to red blood cells and the antierythrocytic auto antibodies changes in bone marrow are indications of bone marrow depression (Abd-Elmaleck et al., 2014). Nevertheless, the type of anaemia diagnosed in the current study suggested a regenerative form, Therefore, the number of reticulocytes will increase in the bloodstream of infected animals. Similar results were reported by Swelum et al. (2014).

The results showing leukocytosis occurring due to significant lymphocytosis in infected camels were in line with results of Egbe-Nwiyi (1994) and Uilenberg (2006). Leukocytosis developed due to the stimulation of lymphoid tissues and stem cells in the bone marrow by Babesia and/or its toxins, and also due to lymphoid depletion and disorders of massive lymphocytes (Weiss \& Wardrop, 2010). Furthermore, lymphocytosis in Babesia infec- 
tion will be more significant if antibodies are formed in response to antigen (Swelum et al., 2014).

The current study proves that $B$. $c a$ balli infected one humped camels had induced coagulation defects. There is little documentation of the impact of camel babesiosis on clotting factors. Variations in clotting factors shown in the present study were also reported by Alsaad (2009) and Abdel Galil et al. (2013) as significant decrease of platelets count (thrombocytopaenia). Hypofibrinogenaemia and prolonged blood clotting time suggested the prevalence of petechial haemorrhages which might be evident in mucous membranes but the decrease of platelets number could also take place because of the depressed bone marrow activity, splenomegaly and expropriation or retention of platelets, which could result from disturbed haemostasis and might be terminated by microthrombosis and infarction of organs like the brain, lungs and intestine (Hussein et al., 2010). In the current work, clotting factors showed obvious deterioration in the clotting system of infected camels with imbalanced regulation which might lead to hyper- and/or hypocoagulation indicating the beginning of disseminated intravascular coagulation (Bick, 2003; Pantanowitz, 2003).

Few studies are available on the topic of cardiac biomarkers in camels. However, the use of specific biomarkers for the evaluation of heart damage is important in the diagnosis of myocardial diseases, as such biomarkers are widely used in confirming the disease status, the risks and clinical decision for the appropriate diagnosis (Adams, 1998). Therefore, in this study, troponin, CpK-MB and LDH concentrations were measured as they resulted in a significant increase in infected camels compared to the control group. Serum cardiac troponins may be evaluated via myocardial damage cells in humans and various animals, as an indicator of myocardial injury (Tharwat et al., 2013). Troponins, are defined as protein molecules that are a part of cardiac and skeletal muscles, while on the contrary, smooth muscle cells do not have troponins (Vishal et al., 2012). Troponins are liberated in response to myocardial injuries. However, ischaemia is the most common causal factor in cardiac muscle damage, which is suspected in the current study, in most cases it could develop due to anaemia (Tharwat et al., 2013). The degree and the duration of creatine phosphokinase myocardial band elevation in serum was nearly within the range of an acute myocardial infarction. Therefore, it is considered that this is due to the effects of an ongoing increase in the enzyme activity as a result of cardiac myopathy that develops in heart problems (Karapinar et al., 2010). Further, the significant increase in $\mathrm{LDH}$ level in infected camels suggest that the increase of cardiac dysrhythmias in the myocardially diseased animals may result from metabolic and electrolyte disorders as LDH enzyme is found in most tissues such as the heart, liver, erythrocyte, leukocytes, and kidney (Alshamsi et al., 2015; Valvona et al., 2016).

\section{CONCLUSIONS}

Based on microscopic examination, various shapes of $B$. caballi were seen in the cytoplasm of erythrocytes in infected camels. Babesia caballi in camels can cause an acute form of disease with haematological changes, significant differences in clotting factors and increase in concentrations of some cardiac biomarkers in infected camels. Therefore, it is a disease that must be taken care of by early diag- 
nosis. The control of ectoparasites is always advised.

\section{ACKNOWLEDGEMENTS}

This study was financially supported by of College of Veterinary Medicine, University of Mosul. The authors thank the expert technical assistance from the Veterinary Clinical $\mathrm{Pa}$ thology laboratory of the Veterinary Teaching Hospital, Department of Internal and Preventive Medicine, College of Veterinary Medicine, University of Mosul and the camels' owners for their cooperation.

\section{REFERENCES}

Abdel Galil, M., A. M. Abdel Gader, A. A. Al Momen, B. B. Marjory, L. C. James, A. H. Ahmed \& F. H. Mansour, 2013. Clotting factor VIII (FVIII) and thrombin generation in camel plasma: A comparative study with humans. Canadian Journal of Veterinary Research, 77, 150-157.

Abd-Elmaleck, B. S., G. H. Abed \& A. M. Mandour, 2014. Some protozoan parasites infecting blood of camels (Camelus dromedarius) at Assiut locality, Upper Egypt. Journal of Bacteriology \& Parasitology, 5, 2-7.

Abdelrahim, I. A., A. A. Ismail, A. M. Majid, A. S. Mohammed, A. M. Ibrahim, M. Allsop \& M. Oosthuizen, 2009. Detection of Babesia caballi in the one-humped camel (Camelius dromedarius) using the reverse line block (RLB) in Sudan. Sudan Journal of Veterinary Research, 24, 69-72.

Adams, J. E., 1998. Cardiac biomarkers: Past, present, and future. American Journal of Critical Care, 7, 418-423.

Al-Amery, A. M., A. A. Faraj \& S. A. Majeed, 2017. Detection of Haemoprotozoa in camels in Al-Najaf province, Iraq. International Journal of Advanced Biological Research, 7, 238-241.

AL-Ani, F. K., 2004. Camel Management and Disease, $1^{\text {st }}$ edn, Al-Sharq Printing Press.
Dar-Ammar Book Publisher, Amman, Jordan.

Al-Naily, Z. H., 2018. Molecular study of some blood parasites in camels in Aliwaniyah province. Master of Science thesis, College of Veterinary Medicine, University of Al-Qadissiyiah.

Al-Obaidi, Q. T., A. Mohd Mokhtar, I. I. AlSultan, A. B. Azlinda \& K.G. K. Mohd Azam, 2016. Equine piroplasmosis in Kelantan, Malaysia: Clinicohemato-biochemical alterations in subclinically and clinically infected equids. Tropical Biomedicine, 33, 619-631.

Alsaad, K. M., 2009. Clinical, hematological and biochemical studies of Anaplasmosis in Arabian one-humped camels (Camelus dromedarius). Journal of Animal and Veterinary Advances, 8, 1794-1797.

Alsaad, K. M., M. A. Al-Amery, T. A. AlHamed \& R. K. Muhsen, 2015. Babesiosis caballi in one humped dromedaries of Basrah province. Basrah Journal of Veterinary Research, 14, 207-214.

Alshamsi, N. S., T. S. Ksiksi \& S. S. Ashraf, 2015. Altered serum enzymes and biochemical levels in Arabian racing camels with bone fractures. Journal of Animal and Plant Sciences, 25, 1072-1080.

Apanaskevich, D. A., A. L. Schuster \& I. G. Horak, 2008. The genus Hyalomma: VII. Redescription of all parasitic stages of $H$. (Euhyalomma) dromedarii and H. (E.) schulzei (Acari: Ixodidae). Journal of Medical Entomology, 45, 817-831.

Ash, L. R. \& T. C. Orihel, 1990. Atlas of Human Parasitology, $3^{\text {rd }}$ edn, ASCP Press, Chicago.

Bick, R. L., 2003. Disseminated intravascular coagulation: Current concepts of etiology, pathophysiology, diagnosis and treatment. Hematology/Oncology Clinics of North America, 17, 149-176.

Bush, B.M., 1975.Veterinary Laboratory Manual, $1^{\text {st }}$ edn, The Gresham Press, London, pp. 113-167. 
Clinical, haematological and blood biochemical parameters in Arabian one-humped camels ....

Ciancaglini, E., P. Fazii \& G. R. Sforza, 2005. The use of differential fluorescent staining method to detect bacteriuria. Clinical Laboratory, 50, 685-688.

Constable, P. D., K. W. Hinchcliff, S. H. Done \& W. Grünberg, 2017. Veterinary medicine: A Textbook of the Diseases of Cattle, hoRses, Sheep, Pigs and Goats, $11^{\text {th }}$ edn, Elsevier Health Sciences.

Egbe-Nwiyi, T. N., 1994. Haematological and pathological studies of camel babesiosis in Nigeria. Bulletin of Animal Health and Production, 42, 287-290.

FAO, 2014. Food and Agriculture Organization of the United Nations. FAO Statistical Yearbook 2014 Asia and the Pacific Food and Agriculture, http://www.fao.org/3/ai3590e.pdf (11 December 2019 date last accessed).

Faraj, A. A. \& A. M. Abd-Al-Amery, 2018. Comparison of the efficacy of different methods in the diagnosis of babesiosis in camels (Camelus dromedarius) in Alnajaf Al-Ashraf Province-Iraq of Najaf - Iraq. Basrah Journal of Veterinary Research, 17, 593-602.

Fritsche, T. R. \& J. W. Smith, 2001. Medical parasitology. In: Clinical Diagnosis and Management by Laboratory Methods, $12^{\text {th }}$ edn, ed J. B. Henry, W. B. Saunders Co., Philadelphia, pp. 1196-1240

Gabrielli, S., S. Otašević, A. Ignjatović, S. Savić, M. Fraulo, V. Arsić-Arsenijević, S. Momčilović \& G. Cancrini, 2015. Canine babesiosis in noninvestigated areas of Serbia. Vector-Borne and Zoonotic Diseases, 15, 535-539.

Ganjali, T. A., 2016. Phylogenetic analysis of camel piroplasmids in Iran based on $18 \mathrm{~s}$ rRNA gene. MSc. Dissertation, Shahid Chamran University of Ahvaz (PER).

Hairgrove, T., M. E. Schroeder, C. M. Budke, S. Rodgers, C. Chung, M. W. Ueti \& M. A. Bounpheng, 2015. Molecular and serological in-herd prevalence of Anaplasma marginale infection in Texas cattle. Preventive Veterinary Medicine, 119, 1-9.
Hassan, S. M. \& D. A. Salih, 2009. Bibliography with abstracts, ticks and tick-borne diseases in the Sudan. $1^{\text {st }}$ edn, Central Laboratory, Ministry of Science and Technology, Khartoum.

Hussein, M. F., R. S. Aljumaah, A. M. Homeida, A. A. Alhaidary, M. A. Alshaikh, A. Gar, O. B. Elnabi Mohammed, S. A. Omer \& W. V. Macasero, 2010. Coagulation profile and platelet parameters of the Arabian sand gazelle (Gazella subgutturosa marica): comparison with humans and camels. Journal of Wildlife Diseases, 46, 1165-1171.

Ibrahim, A. M., A. A. H. Kadle \& H. S. Nyingilili, 2017. Microscopic and molecular detection of camel piroplasmosis in Gadarif State, Sudan. Veterinary Medicine International, 1, 1-5.

Irwin, P. J., 2010. Canine babesiosis. Veterinary Clinics of North America - Small Animal Practice, 40, 1141-1156.

Jasim, H. J., G. Y. Azzal \& R. M. Othman, 2015. Conventional and molecular detection of Babesia caballi and Theileria equi parasites in infected camels in south of Iraq. Basrah Journal of Veterinary Research, 14, 110-121.

Kamani, J., T. A. Usman, E. G. Onyeamaechi, M. A. Usman \& S. M. Kida, 2008. Hemoparasites of camels (Camelus dromedarius) in Maiduguri, Nigeria. Animal Research International, 5, 838-839.

Karapinar, T., D. O. Dabak, T. Kuloglu \& H. Bulut, 2010. High cardiac troponin I plasma concentration in a calf with myocarditis. Canadian Veterinary Journal, 51, 397-399.

Khamesipour, F., A. Doosti, A. Koohi, M. Chehelgerdi, A. Mokhtari-Farsani \& A. A. Chengula, 2015. Determination of the presence of Babesia DNA in blood samples of cattle, camel and sheep in Iran by PCR. Archives of Biological Sciences, 67, 83-90.

Kouam, M. K., V. Kantzoura, A. A. Gajadhar, J. H. Theis, E. Papadopoulos \& G. Theodoropoulos, 2010. Seroprevalence of 
equine piroplasms and host-related factors associated with infection in Greece. Veterinary Parasitology, 169, 273-278.

Leech, N. L., K. C. Barrett \& G. A. Morgan, 2007. SPSS for intermediate statistics: use and interpretation, $1^{\text {st }}$ edn, Lawrence Erlbaum Assoc, USA. pp. 20-51.

Maharan, O. M., 2004. Some studies on blood parasites in camels (Camelus dromedarius) at Shalatin city, Red Sea Governorate. Assiut Veterinary Medical Journal, 50, 172-183.

Pantanowitz, L., 2003. Mechanism of thrombocytopenia in tick born diseases. International Journal of Infectious Diseases, 2 , $1-7$.

Qablan, M. A., M. Sloboda, M. Jirku, M. Oborník, S. Dwairi, Z. S. Amr, P. Horín L. Julius \& D. Modry, 2012. Quest for the piroplasms in camels: Identification of Theileria equi and Babesia caballi in Jordanian dromedaries by PCR. Veterinary Parasitology, 86, 456-460.

Scoles, G. A. \& M. W. Ueti, 2015. Vector ecology of equine piroplasmosis. Annual Review of Entomology, 60, 561-581.

Swelum, A., A. B. Ismael, A. F. Khalaf \& M. A. Abouheif, 2014. Clinical and laboratory findings associated with naturally occurring babesiosis in dromedary camels. Bulletin of the Veterinary Institute in Pulawy, 58, 299-233.

Tharwat, M., F. Al-Sobayil \& S. Buczinski, 2013. Cardiac biomarker changes in camels (Camelus dromedarius) secondary to road transportation. Journal of Veterinary Cardiology, 15, 15-22.

Uilenberg, G., 2006. Babesia - a historical overview. Veterinary Parasitology, 138, 3-10.
Valvona, C. J., H. L. Fillmore, P. B. Nunn \& G. J. Pilkington, 2016. The regulation and function of lactate dehydrogenase A: therapeutic potential in brain tumor. Brain Pathology, 26, 3-17.

Vishal, V. U., T. F. Dhaval, B. M. Jivani, G. Hemant, J. G. Dineshbhai, P. J. Bholanath, \& S. P. Kantibhai, 2012. Cardiac troponin: An emerging cardiac biomarker in animal health. Veterinary World, 5, 508-511.

Weiss, D. J. \& K. J. Wardrop, 2010. Schalm's Veterinary Hematology, $6^{\text {th }}$ edn, Wiley Blackwell

Wernery, U. \& O. R. Kaaden, 2002. Infectious Diseases in Camelids. Blackwell, Vienna, p. 403.

Zhang, J., P. Kelly, J. Li, C. Xu \& C. Wang, 2015. Molecular detection of Theileria spp. in livestock on five Caribbean Islands. BioMed Research International, ID 624728, DOI 10.1155/2015/624728.

Paper received 08.09.2019; accepted for publication 31.10.2019

\section{Correspondence:}

Al-Obaidi Qaes Talb

Department of Internal and Preventive Medicine, College of Veterinary Medicine, University of Mosul, Mosul, Iraq; e-mail: qaesnada1976@gmail.com 